\title{
Demonstration of donor specific unresponsiveness in rat islet allografts: importance of transplant site for induction by cyclosporin $A$ and maintenance
}

\author{
T. Kamei and Y. Yasunami \\ Department of Surgery I, Kyushu University Faculty of Medicine, Fukuoka, Japan
}

\begin{abstract}
Summary. The purpose of the present study was to evaluate the effects of transplant site (the liver via the portal vein vs the renal subcapsular space) on islet allograft survival using cyclosporin A and also to determine whether or not the unresponsiveness obtained is donor specific and how the site selected is related to the maintenance of unresponsiveness. Prolongation of islet allograft survival (WKA/Qdj:RT1 $\rightarrow$ Lewis: $\mathrm{RT}^{1}$ ) was obtained by using hand-picked clean fresh islets as donors and by s.c. administration of cyclosporin A $(30 \mathrm{mg} / \mathrm{kg}$, day $0,1,2)$ when the islets were transplanted into the liver. Eleven out of 15 recipients were normoglycaemic for more than 90 days after transplantation (control mean survival time: $4.4 \pm 1.1$ days, $n=5$ ). However, all the renal subcapsular grafts were rejected within 18 days after transplantation. Two normoglycaemic recipients bearing intrahepatic grafts were challenged with full-thickness donor-strain (WKA/Qdj) skin grafts at 120 days after the islet transplantation. Both re-
\end{abstract}

cipients became diabetic and the skin grafts rejected within 16 days. The nine normoglycaemic recipients were made diabetic again with streptozotocin $(40 \mathrm{mg} / \mathrm{kg})$ between 90 and 120 days after the initial islet transplantation. Re-transplants of fresh donor-strain (WKA/Qdj) islets into the liver $(n=3)$ in the absence of cyclosporin A maintained normoglycaemia in the recipients for more than 60 days, whereas re-transplants of donor-strain islets beneath the kidney capsule were rejected within 20 days. Intrahepatic re-transplants of third party grafts $\left(\mathrm{PVG} / \mathrm{c}: \mathrm{RTl}^{\mathrm{C}}\right)(n=3)$ were rejected after seven days. These findings clearly demonstrate that the donor specific unresponsiveness in rat islet allografts was not only induced but also maintained only when the liver was the site used for implantation of the islets.

Key words: Islet transplantation, cyclosporin A, allograft, tolerance induction, transplant site.
Pancreatic islet transplantation has the potential to become therapeutic procedure for the treatment of human diabetic patients since one of the major limitations for its clinical application, difficulty in isolating an adequate number of donor islets from the human pancreas for transplantation, has now been resolved by the development of new techniques [1-5].

In clinical islet transplantation, many transplant sites have been considered. Different sites may affect the immune response of the recipients to the grafts. The ideal site is one which is safe for the patient with minimal side effects, and where the graft is accepted by induction of donor specific unresponsiveness without continuous immunosuppression to the recipients. The liver via the portal vein [6] and the renal subcapsular space [7], respectively, have been the two major sites used for islet transplantation. The purpose of the present study was to compare the survival of islet allografts transplanted into the liver and the kidney in conjunction with cyclosporin A (CyA) treatment of the recipients and to determine the effect of the site on the induction and maintenance of donor specific unresponsiveness in rat islet allografts.

\section{Materials and methods}

\section{Animals}

WKA $\left.Q d j(R T]^{\mathrm{u}}\right)$ rats were supplied from the Institute for Animal Experiment, Faculty of Medicine, Kyushu University (Fukuoka, Japan) and PVG/c $\left(\mathrm{RT}^{\mathrm{c}}{ }^{\mathrm{C}}\right.$ ) rats, purchased from Seiwa Experimental Animal Ltd. (Fukuoka, Japan) were used as donors. Lewis (RT1 ${ }^{\mathrm{l}}$ ) rats were purchased from Charles River Japan (Kanagawa, Japan) and used as recipients. Diabetes was induced in the recipients by the i.v. injection of streptozotocin (STZ, $60 \mathrm{mg} / \mathrm{kg}$ ). Non-fasting plasma glucose of all the recipients exceeded $22 \mathrm{mmol} / 1$. 

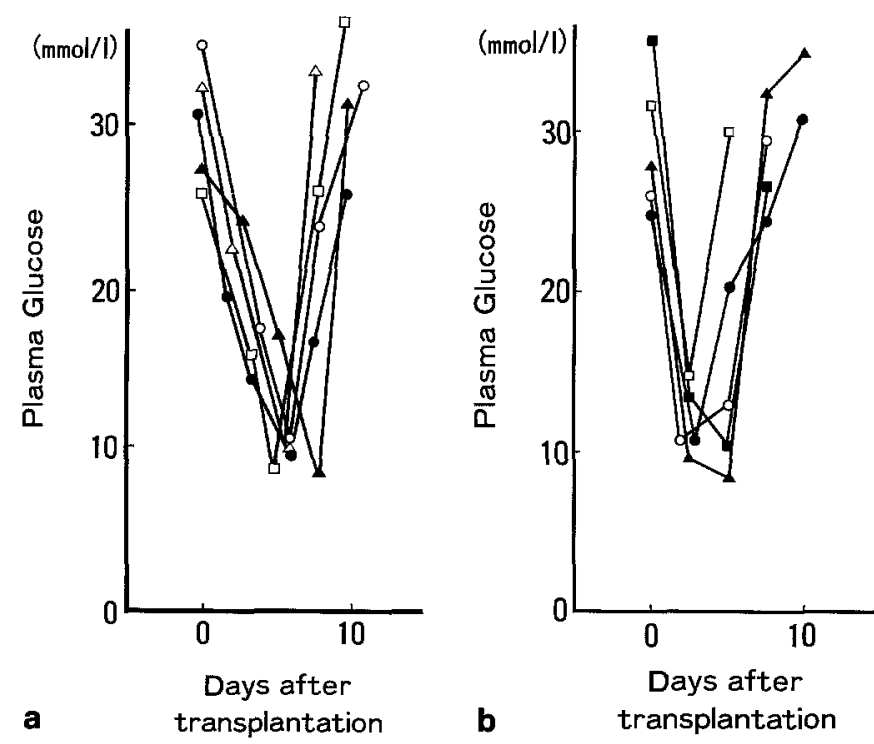

Fig. 1 a and b. Survival of fresh islet allografts. WKA/Qdj(RT1 $\left.1^{u}\right)$ and Lewis $\left(R T 1^{1}\right)$ rats were used as donors and recipients, respectively. Symbols refer to individual animals. All the fresh islet allografts were implanted at day 0 and rejected within 9 days after transplantation. a beneath the kidney capsule, $\mathbf{b}$ into the liver via the portal vein

\section{Islet isolation and transplantation}

Islets were isolated by the collagenase technique [8] and separated by centrifugation on Ficoll-Conray gradients [9]. Islets were picked manually using a Pasteur pipette with the aid of a dissecting microscope. Only clean islets free of ducts, vessels, acinar cells and lymph nodes were selected and used for transplantation. 1400-1500 fresh islets were transplanted either into the liver via the portal vein [10] or beneath the kidney capsule $[11,12]$.

\section{Cyclosporin A}

Cyclosporin A (CyA; gift from Sandoz Company, Basel, Switzerland) was dissolved in olive oil $(20 \mathrm{mg} / \mathrm{ml})$ and injected s.c. as a dose of $30 \mathrm{mg} / \mathrm{kg}$ into rats in appropriate groups at day 0,1 and 2 after transplantation.

\section{Criteria for rejection}

Non-fasting plasma glucose levels and body weights were monitored three times a week in rats from all groups. Plasma glucose was measured using a Beckman glucose analyser (Beckman Instruments Japan, Tokyo, Japan). Rejection was considered to have occurred when the plasma glucose levels exceeded $11 \mathrm{mmol} / 1$ on two consecutive determinations with loss of body weight after transplantation.

\section{Morphological study}

All the recipients that were rejecting their grafts were killed for morphological studies of the liver or kidney, depending upon the transplant site, and pancreas when more than two consecutive plasma glucose levels exceeded $22 \mathrm{mmol} / 1$ after transplantation. The entire liver or kidney of each animal was sliced into $2 \mathrm{~mm}$ thick blocks, fixed in Bouins' solution and processed for light microscopy. The sections were stained with haematoxylin and eosin, and aldehyde fuchsin.

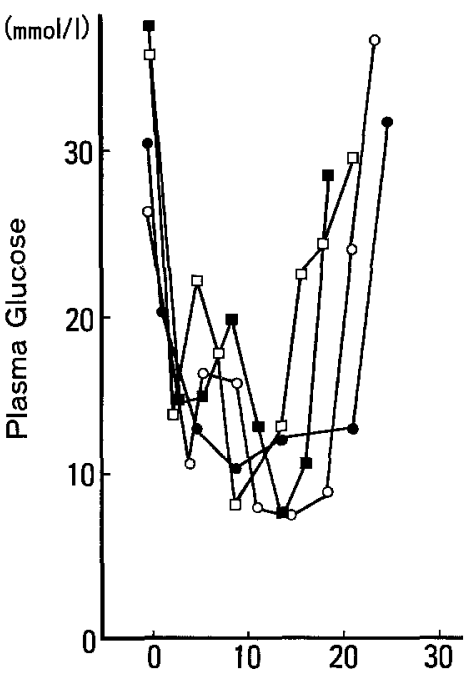

a Days after transplantation

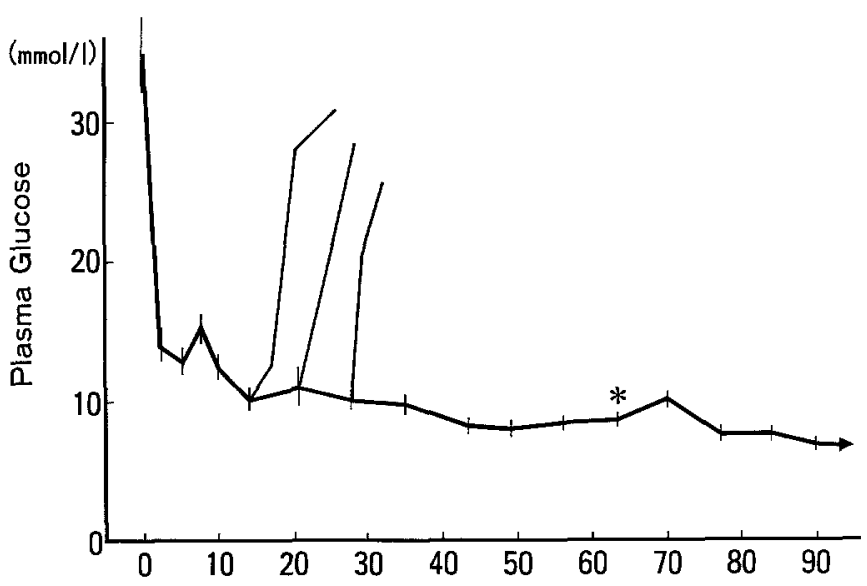

b Days after transplantation

Fig. 2a and b. Effects of cyclosporin A (CyA) on islet allograft survival. Marked prolongation of islet allograft survival was obtained by combination of fresh clean islets as donors and CyA treatment $(30 \mathrm{mg} / \mathrm{kg}$, s.c.) on day 0,1 and 2 to the recipients when the islets were transplanted into the liver via the portal vein. Islet transplantation, a beneath the kidney capsule. Symbols refer to individual animals. b into the liver. Eleven out of 15 recipients were normoglycaemic for more than 90 days after transplantation. * One of the normoglycaemic recipients was killed for morphological studies at 60 days after transplantation. The rest of $\mathbf{1 1}$ normoglycaemic recipients were used for the following studies

\section{Results}

\section{Survival of fresh clean islets}

When WKA/Qdj(RT1 $\left.{ }^{\text {山 }}\right)$ fresh islets were transplanted into the liver via the portal vein of diabetic Lewis $\operatorname{rats}\left(\mathrm{RT}^{\mathrm{l}}\right)$ the mean graft survival (MST) was $4.4 \pm 1.1$ days (mean $\pm \mathrm{SD}, n=5$ ) (Fig. $1 \mathrm{~b}$ ). When the fresh islets were transplanted beneath the kidney capsule, five out of 12 recipients became normoglycaemic and rejected the grafts at 7.2 $\pm 1.1(n=5)$ days after transplantation (Fig. 1 a). The non-fasting plasma 


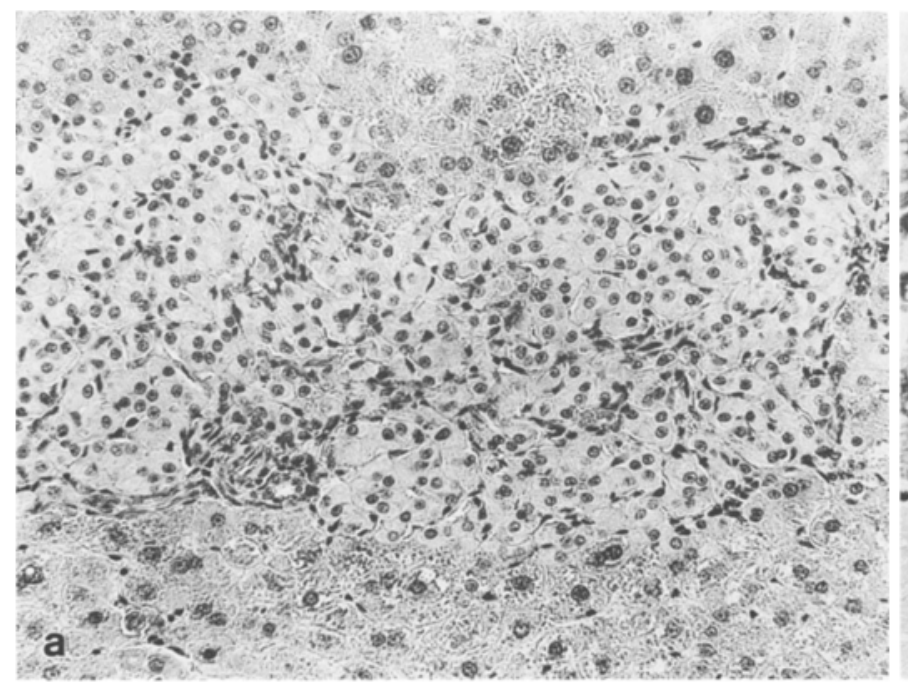

Fig. 3 a and b. Photomicrograph of an islet graft in the liver of a normoglycaemic recipient at 60 days after transplantation. The islet cells appeared intact morphologically. No mononuclear cell infiltration was seen. a haematoxylin and eosin, $\mathbf{b}$ aldehyde fuchsin stain. Original magnification $\times 230$

glucose of the rest of the seven recipients decreased following transplantation and returned to the pre-transplant levels at $6.7 \pm 1.4$ days after transplantation (Table 1). All the grafts were examined histologically and no islet cells were seen in the liver or beneath the renal capsule. Foci of mononuclear cells were present at the graft sites (histology not shown).

\section{Effect of CyA on islet allograft survival}

Four out of nine recipients receiving the renal subcapsular grafts with CyA became normoglycaemic after transplantation and rejected the grafts at $13.0 \pm 2.4$ days $(n=4)$ after transplantation (Fig.2a). The non-fasting plasma glucose of the rest of five recipients decreased following transplantation and returned to the pre-transplant levels at $13.8 \pm 2.9$ days after transplantation. Morphologically the islet grafts were infiltrated by mononuclear cells. Marked prolongation of graft survival was obtained by CyA when the islets were transplanted into the liver via the portal vein. Three out of 15 recipients rejected the grafts at 17,21 and 28 days after transplantation (Fig. 2b). One normoglycaemic recipient at 60 days after transplantation was examined post-mortem and the liver and pancreas examined histologically. The islet cells were found easily in the liver and appeared intact morphologically. No mononuclear cell infiltration was seen (Fig.3). The rest of the 11 recipients bearing the intrahepatic allograft were normoglycaemic for more than 90 days after transplantation and were used for the following studies.

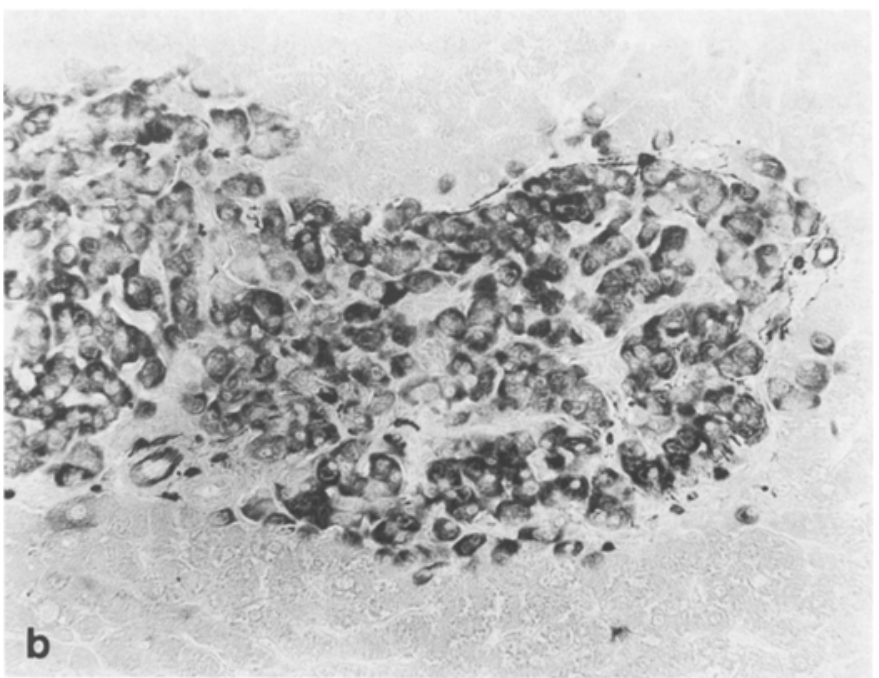

\section{Challenge with donor-strain skin graft}

Two normoglycaemic recipients bearing the intrahepatic islet allografts were challenged with full-thickness donor-strain skin graft (WKA/Qdj) at 120 days after the initial islet transplantation. The skin graft, $1 \mathrm{~cm} \times 1 \mathrm{~cm}$ in size, was transplanted into the back of the recipients and the grafts were fixed by interrupted sutures. Both recipients became diabetic again at 12 and 14 days after skin transplantation (Fig. 4a). The skin grafts became necrotic and were detached due to rejection at 16 days after transplantation (Fig. 4 b).

\section{Re-transplantation of islets}

The rest of the nine normoglycaemic recipients were made diabetic again with STZ $(40 \mathrm{mg} / \mathrm{kg})$ at 90 days after the initial islet transplantation. The dosage of

Table 1. Effects of transplant site on islet allograft survival

\begin{tabular}{|c|c|c|c|c|}
\hline \multirow{2}{*}{$\begin{array}{l}\text { Trans- } \\
\text { plan- } \\
\text { tation } \\
\text { site }\end{array}$} & \multirow{2}{*}{$\begin{array}{l}\text { CyA } \\
(30 \mathrm{mg} / \\
\mathrm{kg} \text { day } 0, \\
1,2)\end{array}$} & \multirow{2}{*}{$\begin{array}{l}\text { Number } \\
\text { of recip- } \\
\text { ients }\end{array}$} & \multicolumn{2}{|l|}{ - Graft survival } \\
\hline & & & $\begin{array}{l}\text { Individual } \\
\text { survival (days) }\end{array}$ & Mean $\pm S D$ \\
\hline Kidney & $\begin{array}{l}- \\
-\end{array}$ & $\begin{array}{l}7^{\mathrm{a}} \\
5\end{array}$ & $4,6,7,7,7,8,8$ & $6.7 \pm 1.4$ \\
\hline $\begin{array}{l}\text { Kidney } \\
\text { (SC) }\end{array}$ & $\begin{array}{l}+ \\
+\end{array}$ & $\begin{array}{l}5^{a} \\
4\end{array}$ & $\begin{array}{l}10,13,13,15,18 \\
10,12,15,15\end{array}$ & $\begin{array}{l}13.8 \pm 2.9 \\
13.0 \pm 2.4\end{array}$ \\
\hline $\begin{array}{l}\text { Liver } \\
\text { (via PV) }\end{array}$ & - & 5 & $3^{a}, 4,4,5,6$ & $4.4 \pm 1.1$ \\
\hline $\begin{array}{l}\text { Liver } \\
\text { (via PV) }\end{array}$ & + & 15 & $\begin{array}{l}17,21,28,>60^{b},>90 \\
>90,>90,>90,>90,>90 \\
>90,>90,>90,>90,>90\end{array}$ & $>74.4 \pm 28.3$ \\
\hline
\end{tabular}

a In the recipients the non-fasting plasma glucose levels decreased following transplantation but the lowest value still exceeded $11 \mathrm{mmol} / \mathrm{l}$. The values indicate the day when the plasma glucose of the recipient returned to the pre-transplant levels after transplantation. ${ }^{b}$ The recipient was autopsied for morphological study at 60 days after transplantation. SC, subcapsular; PV, portal vein; CyA, Cyclosporin A 


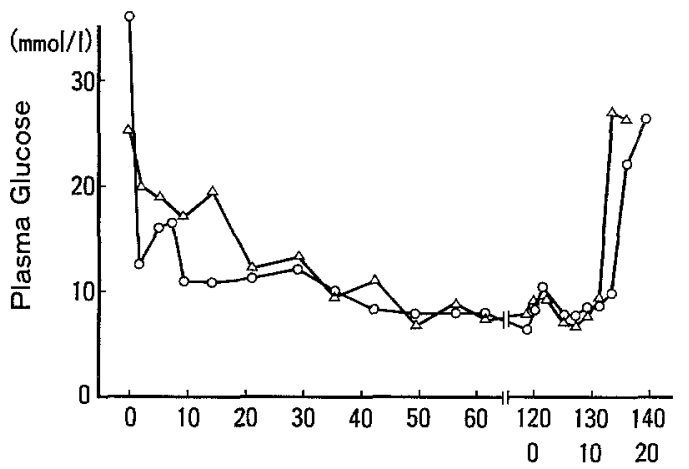

a [ after transplantation

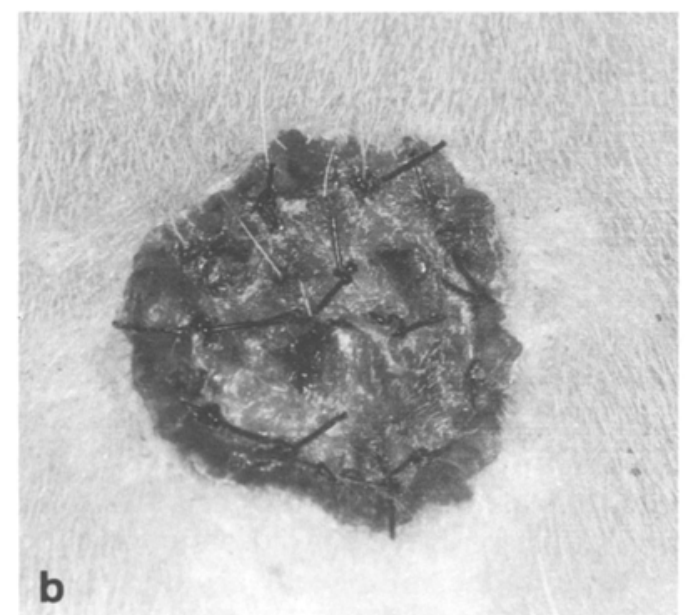

Fig.4a and b. Effects of donor specific skin grafting on the longstanding islet allografts. a The two normoglycaemic recipients bearing the functioning intrahepatic islet allografts (WKA $\rightarrow$ Lewis) were challenged with full thickness donor-strain skin grafts (WKA/Qdj) at 120 days after the islet transplantation. Both recipients became diabetic again within 14 days after the skin grafting. Symbols refer to individual animals. b Photograph of a skin graft at seven days after transplantation. The skin grafts were completely detached due to rejection by 16 days after transplantation

STZ was reduced at this time from 60 to $40 \mathrm{mg} / \mathrm{kg}$ since we found in preliminary studies that recipients weighing over $400 \mathrm{~g}$ sometimes could not tolerate $60 \mathrm{mg} / \mathrm{kg} \mathrm{STZ}$ and died following the injection. The fresh WKA/Qdj islets were transplanted at five days after the STZ injection into the liver $(n=3)$ or beneath the kidney capsule $(n=3)$. PVG/c islets were used as the third party donor and transplanted into the liver $(n=3)$. CyA was not administered at this time. All the recipients receiving the WKA intrahepatic re-grafts were normoglycaemic for more than 60 days after transplantation (Fig. 5 a). The recipients were examined post-mortem 100 days after transplantation and the liver and pancreas examined histologically. The islet cells were found in the liver of all the recipients and appeared intact morphologically. No mononuclear cell infiltration was seen (histology not shown). In contrast, all of the recipients receiving the renal subcapsular grafts became diabetic again within 20 days after transplantation (Fig. 5b). Histologic examination disclosed

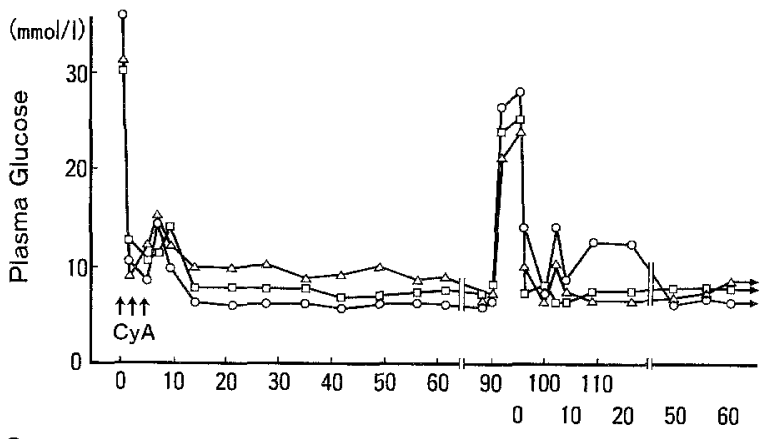

a

Days after transplantation
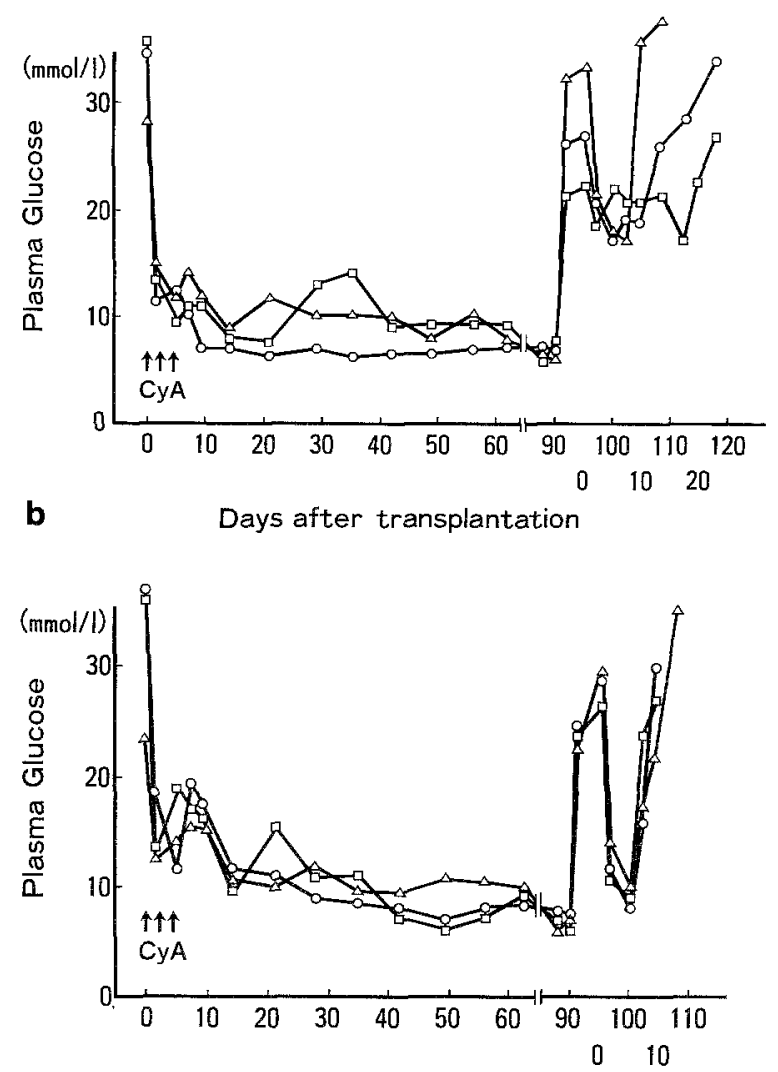

C Days after transplantation

Fig.5a-c. Demonstration of induction and maintenance of donor specific unresponsiveness. The nine normoglycaemic recipients bearing the functioning intrahepatic islet allografts (WKA $\rightarrow$ Lewis) were made diabetic again with streptozotocin (STZ, $40 \mathrm{mg} / \mathrm{kg}$ ) at 90 days after the initial islet transplantation. The donor-strain islets (WKA/Qdj) were transplanted at five days after the STZ injection into the liver via the portal vein (a), or beneath the kidney capsule (b). $\mathrm{PVG} / \mathrm{c}\left(\mathrm{RT}^{\mathrm{C}}\right)$ islets were used as the third party donor and transplanted into the liver (c). Cyclosporin A was not used at this time. The individual line represents the plasma glucose levels of each animal

that the islet grafts were infiltrated with mononuclear cells (Fig. 6). All the PVG/c grafts transplanted into the liver via the portal vein were rejected within seven days after transplantation (Fig. $5 \mathrm{c}$ ). No islet cells were identified in the liver and small foci of mononuclear cells were seen. 


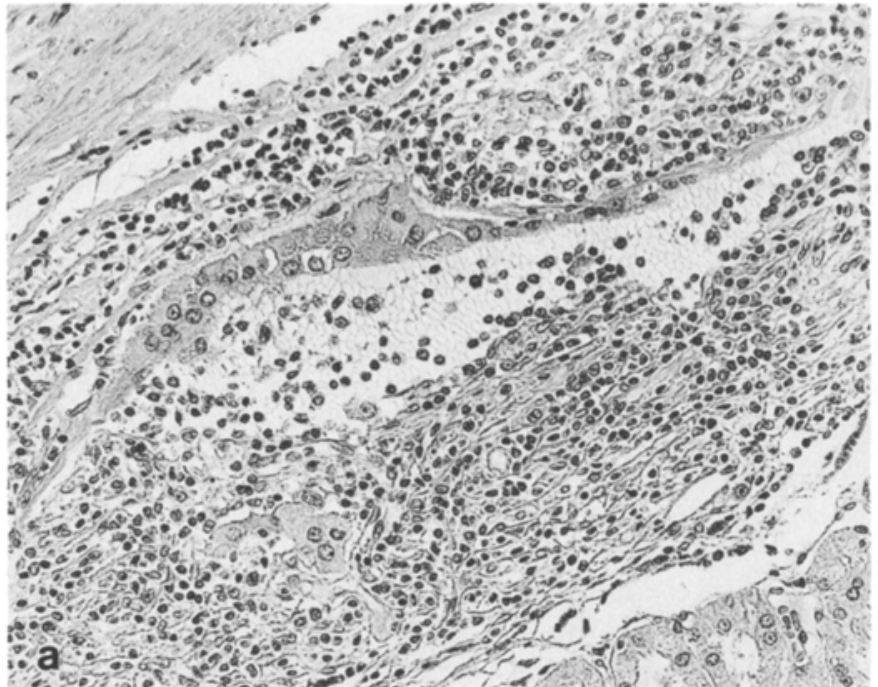

Fig. 6a and b. Photomicrograph of islet cells beneath the kidney capsule of a recipient rejecting the grafts after re-transplantation of the donor-strain islets. a hacmatoxylin and eosin, $\mathbf{b}$ aldehyde fuchsin stain. Original magnification $\times 100$

\section{Different donor-recipient strain combination}

To determine whether the prolongation of the intrahepatic islet allograft survival by CyA is obtained in another donor-recipient strain combination, $\mathrm{PVG} / \mathrm{c}$ islets were used as donors, instead of WKA/Qdj islets and transplanted into the liver of the STZ-diabetic Lewis recipients. CyA was administered s.c. for three days as in the other groups. All the recipients $(n=4)$ were nor-

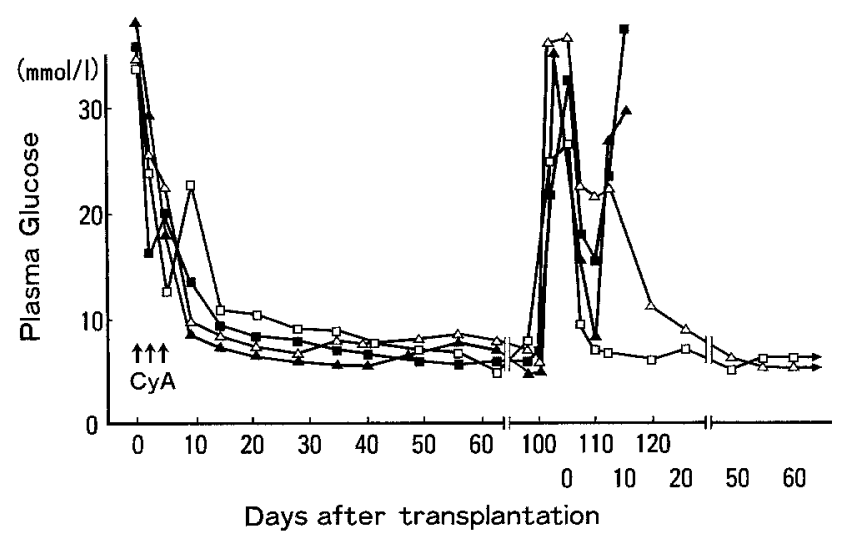

Fig.7. Effects of a different donor-recipient strain combination on induction and maintenance of donor specific unresponsiveness. $\left.\mathrm{PVG} / \mathrm{c}(\mathrm{RT})^{\mathrm{C}}\right)$ and Lewis( $\left.\mathrm{RTl}^{\mathrm{l}}\right)$ rats were used as donors and recipients, respectively. WKA/Qdj(RT1 $)$ rats were used as the third party donor. All the recipients $(n=4)$ were normoglycaemic at 90 days after transplantation by the intraportal islet grafting and cyclosporin A treatment. The recipients were made diabetic again with streptozotocin $(40 \mathrm{mg} / \mathrm{kg})$ and the $\mathrm{PVG} / \mathrm{c}$ or WKA $/ \mathrm{Qdj}$ islets were transplanted into the liver. Symbols $\Delta, \mathbf{\square}$ refer to WKA islets; $\Delta, \square$ to PVG islets. The individual line represents the plasma glucose of each animal

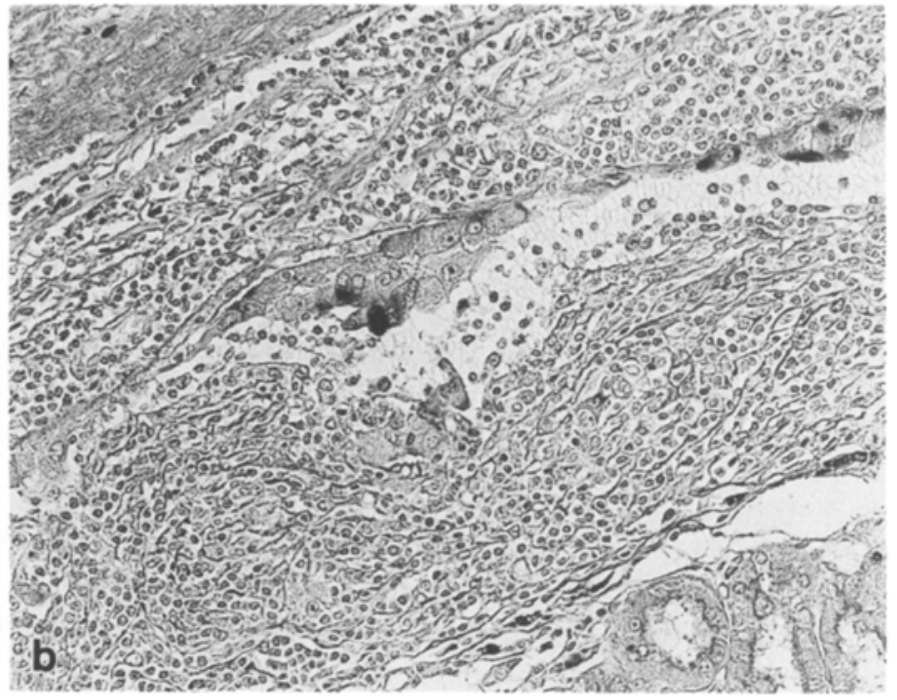

moglycaemic for more than 90 days after transplantation (Fig. 7). The recipients were made diabetic again with STZ $(40 \mathrm{mg} / \mathrm{kg})$ at 90 days after transplantation. The islets from PVG/c or WKA/Qdj, which was used as the third party donor in this situation, were transplanted into the liver via the portal vein. CyA was not administered at this time. All the recipients receiving the donor-strain PVG/c grafts $(n=2)$ were normoglycaemic for more than 60 days after transplantation. In contrast, all the recipients receiving the third party (WKA/Qdj) grafts $(n=2)$ rejected the grafts within seven days after transplantation (Fig. 7).

\section{Discussion}

These findings clearly demonstrate that the donor specific unresponsiveness in rat islet allografts is not only induced but also maintained when the liver is used as the site for islet transplantation combined with shortterm CyA administration to the recipients.

Prolongation of rat islet allograft survival has been achieved by various pre-treatment regimes of donor islets such as low temperature culture [13, 14], anti-Ia antibody treatment [14], reaggregate formation of islets from single islet cells [15] and ultraviolet irradiation [16]. The combined use of immunosuppressive agents to the recipients such as anti-lymphocyte serum [13] or CyA $[14,15,17]$ is also needed to prolong graft survival across the major histocompatible barrier in rats. The objective of the pre-treatment of donor islets is to reduce or modify passenger lymphoid cells in the donor islets which are believed to be responsible for the induction of immune rejection. Recently Dibelius et al. [18] reported a prolongation of islet allograft survival in rats with untreated fresh, donor islets with CyA treatment of the recipients. They employed neutral red to stain and identify islets during the isolation procedure and obtained highly pure islet preparations. These pure islet 
preparations were free of acinar cells, vessels, ducts and lymph nodes and thus contained fewer "passenger lymhoid cells" than present in impure preparations. Previously the importance of using clean fresh islets as donors from the point of preventing immune rejection has been reported by Terasaka et al. [14], Goto et al. [19] and Yasunami et al. [12]. In the present study, we demonstrated a marked prolongation of rat islet allograft survival in different donor-recipient combination using untreated, donor fresh clean islets transplanted into the liver via the portal vein with temporary CyA treatment of the recipients (MST, $>74.4 \pm 28.3$ days, $n=15$ ). This marked prolongation of islet allograft survival was not obtained when the islets were transplanted in the kidney capsule (MST, $13.0 \pm 2.4$ days, $n=4$ ). This finding is important since it indicates that the different transplant sites may affect immune response of the recipients to the grafts. Gores et al. [20] reported a decreased rejection rate in the murine islet transplant model when the liver was a site of choice for transplantation vs the renal subcapsular site. Sullivan et al. reported prolongation of islet xenograft survival (hamster to mouse) when low temperature cultured islets were transplanted beneath the renal capsule [21]. Also in islet xenograft model (rat to mouse) Yasunami et al. [12] reported a prolonged graft survival when cultured $\left(37^{\circ} \mathrm{C}\right)$ clean islets were transplanted beneath the renal capsule. Thus, the donor-recipient strain combination in allografts, species barriers in xenografts, the type of pre-treatment to the donor islets and the type of immunosuppression to the recipients are variables that affect the survival of the islet grafts. Thus, it appears that in each transplant site a proper combination of donor pretreatment and/or recipient immunosuppression might be needed for prolongation of graft survival.

There are conflicting findings on the maintenance of specific immune unresponsiveness in established islet allografts. In a murine model Faustman et al. [22] demonstrated that mice bearing islet allograft were partially tolerant to donor-strain skin allografts. In contrast, Gores et al. showed a lack of tolerance to donor-strain skin grafts in mice bearing long-standing islet allografts [23]. Those conflicting results may be due to differences in the procedure employed for induction of unresponsiveness. In rat allografts Zitron et al. [24] obtained evidence of induction of specific unresponsiveness in rats bearing established islet allografts using low temperature culture and a single injection of anti-lymphocyte serum to prevent rejection of the allografts. In the present study we employed a model of retransplants of donor islets and demonstrated a donor specific unresponsiveness in rats bearing intrahepatic islet allografts. However, the unresponsiveness did not permit donor-strain skin grafts to survive, and the skin grafts induced rejection of the initial islet allografts. Also, the donor specific re-grafts could survive only when grafted into the liver, not beneath the kidney capsule. Thus, the unresponsiveness demonstrated by the present study seems to be "local unresponsiveness" in the liver.

Recently, Qian et al. $[25,26]$ reported that in mice, the i.v. administration of allogenic splenocytes induced delayed-type hypersensitivity response, whereas the intraportal administration of allogenic lymphocytes produced donor specific unresponsiveness and prevention of delayed hypersensitivity. These findings indicate the importance of the intrahepatic site for the induction of specific unresponsiveness. The mechanisms involved in the induction of unresponsiveness in the liver site is unknown but it may be due to the processing and presentation of donor antigens (by Kupffer cells) in the liver.

The present study demonstrates the importance of transplant site for the induction and maintenance of unresponsiveness in islet allografts, which may be of importance in clinical islet transplantation.

Acknowledgements. The authors gratefully acknowledge Prof. P.E.Lacy, Department of Pathology, Washington University School of Medicine (St. Louis, Mo, USA), for his review and comments on the manuscript, and Prof. F. Nakayama, Department of Surgery I, Kyushu University Faculty of Medicine (Fukuoka, Japan), for his advice in conducting this study. This work was supported by Grant-inAid for Scientific Research from the Ministry of Education, Science and Culture, Japan and by the Fujisawa Foundation.

\section{References}

1. Horaguchi A, Merrell RC (1981) Preparation of viable islet cells from dogs by a new method. Diabetes 30: 455-458

2. Lacy PE, Lacy ET, Finke EH, Yasunami Y (1982) An improved method for the isolation of islets from the beef pancreas. Diabetes 31 [Suppl 4]: 109-111

3. Gray DWR, Mcshane P, Grant A, Morris PJ (1984) A method for the isolation of islets of Langerhans from the human pancreas. Diabetes 33: 1055-1061

4. Scharp DW, Lacy PE, Finke EH, Olack B (1987) Low temperature culture of human islets isolated by the distention method and purified with Ficoll or Percoll gradients. Surgery 102: 869-879

5. Ricordi C, Lacy PE, Finke EH, Olack BJ, Scharp DW (1988) Automated method for isolation of human pancreatic islets. Diabetes 37: 413-420

6. Kemp CB, Knight MB, Scharp DW, Lacy PE, Ballinger WF (1973) Transplantation of isolated pancreatic islets into the portal vein of diabetic rats. Nature 244: 447

7. Bown KM, Anchus L, Lafferty KJ (1980) Successful allotransplantation of mouse pancreatic islets to nonimmunosuppressed recipients. Diabetes 29 [Suppl 1]: 98-104

8. Lacy PE, Kostianovky M (1967) Method for the isolation of intact islets of Langerhans from the rat pancreas. Diabetes 16: 35-39

9. Okeda T, Ono J, Takaki R, Todo S (1979) Simple method for the collection of pancreatic islets by the use of Ficoll-Conray gradient. Endocrinol Japon 26: 495-499

10. Kemp CB, Knight MJ, Scharp DW, Ballinger WF, Lacy PE (1973) Effect of transplantation site on the results of pancreatic islet isografts in diabetic rats. Diabetologia $9: 486-491$

11. Lacy PE, Finke EH, Janney CG, Davie JM (1982) Prolongation of islet xenograft survival by in vitro culture of rat megaislets in $95 \%$ $\mathrm{O}_{2}$. Transplantation 33: 588-592 
12. Yasunami Y, Lacy PE, Davie JM, Finke EH (1983) Prolongation of islet xenograft survival (rat to mouse) by in vitro culture at $37^{\circ} \mathrm{C}$. Transplantation $35: 281-284$

13. Lacy PE, Davie JM, Finke EH (1979) Prolongation of islet allograft survival following in vitro culture $\left(24^{\circ} \mathrm{C}\right)$ and a single injection of ALS. Science 204: 312-313

14. Terasaka R, Lacy PE, Hauptfeld V, Bucy RP, Davie JM (1986) The effect of cyclosporin A, low-temperature culture and anti-Ia antibodies on prevention of rejection of rat islet allografts. Diabetes 35: $83-88$

15. Kakizaki K, Basadonna G, Merrell RC (1987) Allotransplantation of islet endocrine reaggregates. Diabetes 36: 315-319

16. Lau H, Reemtsma K, Hardy MA (1984) Prolongation of rat islet allograft survival by direct ultraviolet irradiation of the graft. Science 223: 607-609

17. Lau H, Reemtsma K, Hardy MA (1984) The use of direct ultraviolet irradiation and cyclosporine in facilitating indefinite pancreatic islet allograft acceptance. Transplantation 38: 566-569

18. Dibelius A, Korigsberger $\mathrm{H}$, Walter P, Permanetter W, Brendel W, Specht BU (1986) Prolonged reversal of diabetes in the rat by transplantation of allogenic islets from a single donor and cyclosporine treatment. Transplantation 41: 426-431

19. Gooth M, Maki T, Satomi S, Porter J, Monaco AP (1986) Immunological characteristics of purified pancreatic islet grafts. Transplantation $42: 387-390$

20. Gores PF, Rabe F, Sutherland DER (1987) Prolonged survival of intraportal versus subrenal capsular transplanted islet allografts. Transplantation 43: 747-749

21. Sullivan FP, Ricordi C, Hauptfeld V, Lacy PE (1987) Effect of low-temperature culture and site of transplantation on hamster islet xenograft survival (hamster to mouse). Transplantation 44: 465-468
22. Faustman DL, Hauptfeld V, Davie JM, Lacy PE (1985) Prolonged survival of donor skin grafts on mice bearing established islet of Langerhans transplants. Transplantation 40: 216-218

23. Gores PF, Sutherland DER, Platt JL, Bach FH (1987) Lack of tolerance to donor-strain skin grafts in mice with established islet allografts. Transplantation 43: 749-750

24. Zitron M, Ono J, Lacy PE, Davie JM (1981) Active suppression in the maintenance of pancreatic islet allografts. Transplantation 32: $156-158$

25. Qian J-h, Hashimoto T, Fujiwara H, Hamaoka T (1985) Studies on the induction of tolerance to alloantigens. I. The abrogation of potentials for delayed-type hypersensitivity responses to alloantigens by portal venous inoculation with allogenic cells. J Immunol 134: 3656-3661

26. Qian J-H, Kokudo S, Sato S, Hamaoka T, Fujiwara H (1987) Tolerance induction of alloreactivity by portal venous inoculation with allogenic cells followed by the injection of cyclophosphamide. I. Specific suppression of alloreactive cytotoxic and delayed-type hypersensitivity responses as well as allograft rejection. Transplantation 43: 538-543

Received: 31 March 1989

and in revised form: 14 July 1989

Dr. Y. Yasunami

Department of Surgery I

Kyushu University Faculty of Medicine

3-1-1, Maedashi, Higashi-ku

Fukuoka 812

Japan 